\title{
Content and Accessibility of United States Medical School Websites During COVID-19 and the Online Interview Season
}

Jordan Pollock

Mayo Clinic

M. Lane Moore

Mayo Clinic

Jacob Smith

Mayo Clinic

Jonny Woolstenhulme

University of Utah

Dane Markham

Mayo Clinic

Joshua Rhees

Brigham Young University

Kenneth Poole ( $\square$ poole.kenneth@mayo.edu )

Mayo Clinic Arizona 13400 E Shea Blvd. Scottsdale, AZ 85259 314.323.5729

Naresh Patel

Mayo Clinic

\section{Research Article}

Keywords: Medical school, Medical school education, Medical school website, Medical school website content, Medical school application, Medical school applicant, COVID-19, Online interview, Medical school interview

Posted Date: January 22nd, 2021

DOI: https://doi.org/10.21203/rs.3.rs-147236/v1

License: (1) (1) This work is licensed under a Creative Commons Attribution 4.0 International License.

Read Full License 


\section{Abstract}

\section{Background}

Most medical school applicants use the internet as a source of information when applying for medical school. Previous analyses have evaluated residency and fellowship websites, however, an in-depth analysis regarding medical school websites is lacking.

\section{Methods}

We evaluated 192 United States medical school websites for presence or absence of 39 items relevant to medical school applicants. Items fell into 7 general categories: curriculum, research, demographics of incoming class, admissions information, faculty, financial aid, and social.

Results

Of the 192 websites evaluated (152 allopathic and 40 osteopathic schools), websites contained a mean of 23 items (59\%) with a standard deviation of 4.2 items.

\section{Conclusion}

Our study examining United States Medical School websites revealed a lack of online information for medical school applicants. As medical school interviews transition to being online during the COVID-19 pandemic, the importance of the medical school website to applicants becomes increasingly crucial. The information contained in our study could be used to improve accessibility and information on medical school websites, which could help both applicants and medical schools themselves.

\section{Background}

Medical school is highly competitive. The acceptance rate of admissions was $41.9 \%$ from 2017 through 2020 , with an increasing number of applicants each year - 44,869,51,067, and 52,326 applicants in 2017, 2018, and 2019, respectively.[1] Prospective medical students traditionally obtained information about different medical schools through Medical School Admissions Requirement (MSAR) paper book, summer programs, school advisors, and fairs sponsored by undergraduate institutions. With the advent of the internet, the Association of American Medical Colleges (AAMC) suggests looking at each schools' website for program information.[2] In May 2020, a group of national medical education organizations named the Coalition for Physician Accountability made specific recommendations to medical schools and residencies due to the COVID-19 pandemic. These recommendations are predicted to affect at least the 2020 through 2021 application cycle, and will significantly limit opportunities for personal interactions between medical school applicants and medical schools.[3] Accordingly, website development, content, and accessibility is increasingly important for medical schools. Prior studies have evaluated these factors among residency and fellowship programs, resulting in various 
recommendations for areas of improvement among their respective program websites to both help applicants and increase recruitment. [4-10]

Comprehensive websites can help applicants make informed decisions, providing them with access to information they deem important. For the application cycle of 2019 to 2020, medical school applicants applied to an average of 17 medical schools despite according to data recently released by the Association of American Medical colleges.[1] Medical school applications and interviews are costly for both applicants and programs. Providing applicants with more information to guide decisions regarding which programs to apply and interview at stands to benefit both parties, especially if it results in a better matching of applicants likely to fit a school. Medical schools also stand to benefit from better matching of applicants, as many institutions fill residency positions with recent graduates of their own programs. The astounding number of applications could be due to the increasingly competitive nature of medical school or stress and concern for medical school acceptance. These factors may be accentuated during the COVID-19 pandemic as the Medical College Admissions Test has become delayed, and many service and shadowing opportunities have been cancelled.[11] In addition, the number of applications could be augmented due to lack of availability of information on medical school websites, prompting students to apply to more programs than they are realistically interested in.

Information sources such as the MSAR online database and the American Osteopathic Association (AOA) website were designed to assist medical school applicants while applying for medical school.[12, 13] Given the growing reliance on technology to do personal research on different medical schools, the need for prospective medical students to find robust, consistent information online will continue to increase. The main purpose of our study is to provide an in-depth analysis of medical school website content and to assess the functionality of MSAR and AOA for prospective medical school applicants. To our knowledge, this study is the first to do an in-depth analysis of medical school websites in the United States.

\section{Methods}

The methods of our study were adapted from a well-conceived study examining otolaryngology residency website content.[5] Our study was exempt from Institutional Review Board (IRB) approval because it involves publicly available information. A list of 192 medical school names and website links were obtained from Medical School and Admissions Requirements (MSAR) online database and the American Osteopathic Association (AOA) website in May 2020. We evaluated both information sources for functionality by determining whether the link provided on MSAR or AOA led directly to the medical school homepage or required multiple clicks to get to the medical school homepage. When a link to a program was not available on MSAR or AOA website, we performed a Google search to find the program website. Medical schools without a functional website, or a website that could not be found, were excluded. The data were collected by four authors (JW, JS, DM, JR) between May 2020 and June 2020. Data gatherers searched the websites of these programs for 39 items listed in Table 1. These items were later divided into 7 categories for further analysis: curriculum, research, demographics of incoming class, admissions 
information, faculty, financial aid, and social. The items and categories included in our study are based off variables many applicants deem as necessary or desirable information, as well as variables we believe are important to medical school applicants.[14] We also included items from a variety of studies examining the quality of residency website content, and based our 7 categories off these studies.[4-6, 9, 10] Some of these factors on medical school websites could be more important to applicants than other factors, as suggested by studies examining how medical students choose a residency program.[15] However, we controlled for this by examining a large number of items (39) on each website and based these items on a variety of studies, as previously described. 
Table 1

A comparison of variables found on US MD and US DO medical school wesbites.

\section{Comparison Variables}

Number of MD

Programs (\% of all MD Programs)
Number of DO

Programs (\% of all

DO Programs)
Number of MD + DO

Programs (\% of all MD and DO Programs)

\section{Curriculum}

Yearly Overview

Listed

Attendance Policy

Listed

Evaluation

(Grading) Policy

Listed

Dual Degree

Programs Listed

$146(96.1 \%)$

$40(100.0 \%)$

$186(96.9 \%)$

0.471

$42(27.6 \%)$

$10(25.0 \%)$

$52(27.1 \%)$

0.973

$57(37.5 \%)$

$8(20.0 \%)$

65 (33.9\%)

0.147

Programs Listed

$127(83.6 \%)$

$21(52.5 \%)$

$148(77.1 \%)$

0.108

Match results listed

$103(67.8 \%)$

$29(72.5 \%)$

$132(68.8 \%)$

0.458

Average USMLE

$13(8.6 \%)$

$0(0.0 \%)$

$13(6.8 \%)$

0.077

Step 1 Score

USMLE Step 1 Pass

rate

$29(19.1 \%)$

$1(2.5 \%)$

$30(15.6 \%)$

0.026

Average COMLEX

score

COMLEX pass rate

listed

Facility Description

75 (49.3\%)

$4(10.0 \%)$

$4(10.0 \%)$

Rotation

Information

$109(71.7 \%)$

$34(85.0 \%)$

34 (85.0\%)

Provided

Research

Description of

Research

Opportunities

Research

Requirement

Information Listed

$127(83.6 \%)$

$32(80.0 \%)$

159 (82.8\%)

0.821

$30(75.0 \%)$

105 (54.7\%)

0.018

$32(80.0 \%)$

$141(73.4 \%)$

0.325

Demographics of Incoming Class

Demographics are listed

97 (63.8\%)

$20(50.0 \%)$

$117(60.9 \%)$

0.526

0.021

$3(7.5 \%)$

$48(25.0 \%)$

0.021 


\begin{tabular}{|c|c|c|c|c|}
\hline $\begin{array}{l}\text { Comparison } \\
\text { Variables }\end{array}$ & $\begin{array}{l}\text { Number of MD } \\
\text { Programs (\% of all } \\
\text { MD Programs) }\end{array}$ & $\begin{array}{l}\text { Number of DO } \\
\text { Programs }(\% \text { of all } \\
\text { DO Programs) }\end{array}$ & $\begin{array}{l}\text { Number of MD + DO } \\
\text { Programs (\% of all MD } \\
\text { and DO Programs) }\end{array}$ & $\begin{array}{l}\mathrm{P} \\
\text { value }\end{array}$ \\
\hline MCAT Stats Listed & $111(73.0 \%)$ & $29(72.5 \%)$ & $140(72.9 \%)$ & 0.698 \\
\hline GPA Stats Listed & $115(75.7 \%)$ & $26(65.0 \%)$ & $141(73.4 \%)$ & 0.770 \\
\hline $\begin{array}{l}\text { State-by-State Data } \\
\text { Listed }\end{array}$ & $27(17.8 \%)$ & $9(22.5 \%)$ & $36(18.8 \%)$ & 0.397 \\
\hline \multicolumn{5}{|l|}{ Financial Aid } \\
\hline $\begin{array}{l}\text { Average Financial } \\
\text { Aid Listed }\end{array}$ & $7(4.6 \%)$ & $0(0.0 \%)$ & $7(3.6 \%)$ & 0.194 \\
\hline $\begin{array}{l}\text { Info on How to } \\
\text { Apply For Aid Listed }\end{array}$ & $140(92.1 \%)$ & $39(97.5 \%)$ & $179(93.2 \%)$ & 0.422 \\
\hline $\begin{array}{l}\text { Financial Aid Office } \\
\text { Contact Info Listed }\end{array}$ & $135(88.8 \%)$ & $39(97.5 \%)$ & $174(90.6 \%)$ & 0.317 \\
\hline $\begin{array}{l}\text { Scholarship } \\
\text { Opportunities Listed }\end{array}$ & $99(65.1 \%)$ & 37 (92.5\%) & $136(70.8 \%)$ & 0.022 \\
\hline $\begin{array}{l}\text { Example Budget } \\
\text { Listed }\end{array}$ & 137 (90.1\%) & $33(82.5 \%)$ & $170(88.5 \%)$ & 0.999 \\
\hline \multicolumn{5}{|l|}{ Admissions Info } \\
\hline $\begin{array}{l}\text { Required Pre-Med } \\
\text { Courses Listed }\end{array}$ & $145(95.4 \%)$ & $40(100.0 \%)$ & $185(96.4 \%)$ & 0.448 \\
\hline $\begin{array}{l}\text { Letters of Rec } \\
\text { Requirements } \\
\text { Listed }\end{array}$ & $141(92.8 \%)$ & 37 (92.5\%) & $178(92.7 \%)$ & 0.644 \\
\hline $\begin{array}{l}\text { Admissions Office } \\
\text { Contact Info listed }\end{array}$ & $144(94.7 \%)$ & 38 (95.0\%) & $182(94.8 \%)$ & 0.618 \\
\hline $\begin{array}{l}\text { Waitlist Information } \\
\text { Provided }\end{array}$ & $55(36.2 \%)$ & $5(12.5 \%)$ & $60(31.3 \%)$ & 0.030 \\
\hline $\begin{array}{l}\text { Early Decision } \\
\text { Program Info } \\
\text { Provided }\end{array}$ & 89 (58.6\%) & $7(17.5 \%)$ & $96(50.0 \%)$ & 0.003 \\
\hline $\begin{array}{l}\text { Acceptance Rate } \\
\text { Listed }\end{array}$ & 79 (52.0\%) & $14(35.0 \%)$ & $93(48.4 \%)$ & 0.288 \\
\hline $\begin{array}{l}\text { In vs Out-of-State } \\
\text { Preference listed }\end{array}$ & $59(38.8 \%)$ & $12(30.0 \%)$ & 71 (37.0\%) & 0.592 \\
\hline $\begin{array}{l}\text { Interview/Decision } \\
\text { Timing Listed }\end{array}$ & $115(75.7 \%)$ & $17(42.5 \%)$ & $132(68.8 \%)$ & 0.058 \\
\hline
\end{tabular}




\begin{tabular}{|c|c|c|c|c|}
\hline $\begin{array}{l}\text { Comparison } \\
\text { Variables }\end{array}$ & $\begin{array}{l}\text { Number of MD } \\
\text { Programs (\% of all } \\
\text { MD Programs) }\end{array}$ & $\begin{array}{l}\text { Number of DO } \\
\text { Programs (\% of all } \\
\text { DO Programs) }\end{array}$ & $\begin{array}{l}\text { Number of MD + DO } \\
\text { Programs (\% of all MD } \\
\text { and DO Programs) }\end{array}$ & $\begin{array}{l}\mathrm{P} \\
\text { value }\end{array}$ \\
\hline $\begin{array}{l}\text { U.S. News Ranking } \\
\text { Listed }\end{array}$ & $28(18.4 \%)$ & $2(5.0 \%)$ & $30(15.6 \%)$ & 0.078 \\
\hline \multicolumn{5}{|l|}{ Social Environment } \\
\hline $\begin{array}{l}\text { Student Wellness } \\
\text { Resources Listed }\end{array}$ & $136(89.5 \%)$ & $36(90.0 \%)$ & $172(89.6 \%)$ & 0.615 \\
\hline $\begin{array}{l}\text { Med School Social } \\
\text { Media link(s) Listed }\end{array}$ & $129(84.9 \%)$ & 33 (82.5\%) & $162(84.4 \%)$ & 0.759 \\
\hline $\begin{array}{l}\text { Description of Area } \\
\text { Activities/Highlights } \\
\text { Listed }\end{array}$ & $106(69.7 \%)$ & $28(70.0 \%)$ & $134(69.8 \%)$ & 0.665 \\
\hline $\begin{array}{l}\text { Clubs/Interest } \\
\text { Groups Listed }\end{array}$ & $122(80.3 \%)$ & 33 (82.5\%) & $155(80.7 \%)$ & 0.555 \\
\hline \multicolumn{5}{|l|}{ Faculty } \\
\hline Faculty Listed & $131(86.2 \%)$ & $38(95.0 \%)$ & $169(88.0 \%)$ & 0.313 \\
\hline Photos Listed & $112(73.7 \%)$ & $32(80.0 \%)$ & $144(75.0 \%)$ & 0.394 \\
\hline $\begin{array}{l}\text { Student/Faculty } \\
\text { Ratio Listed }\end{array}$ & 33 (21.7\%) & $4(10.0 \%)$ & 37 (19.3\%) & 0.186 \\
\hline $\begin{array}{l}\text { Faculty Research } \\
\text { Interests Listed }\end{array}$ & $109(71.7 \%)$ & $23(57.5 \%)$ & $132(68.8 \%)$ & 0.563 \\
\hline
\end{tabular}

As the data contained in residency websites can be subjective, we created a standardized process to evaluate the websites, similar to the previous studies in other specialties.[4-8] First, we only searched for the presence or absence of items, with no attempt made to grade the quality or accuracy of the content. Second, any information that was not directly listed on medical school website was excluded, such as links to external materials or websites, which usually contained general, non-specific information rather than medical school-specific information. Lastly, data were gathered independently by four authors for the same ten programs and compared for agreement. All authors went through all items again together, noting where disagreement occurred. Ambiguity in exclusion and inclusion criteria was resolved and adjusted accordingly upon agreement by all authors. After this instruction, data collectors independently gathered the data for all websites (JW, JS, DM, JR). For the remaining websites, disagreement was resolved by a fifth author (LM). We performed a descriptive analysis of the data, including means and standard deviations. Additionally, a sub-analysis was performed to determine whether a difference exists in website quality and accessibility among top 25 medical schools and the other 167 schools in our study. We referred to the 2021 data from the US News and World Report website for best medical schools 
for research, which attempts to rank medical schools based on a variety of criteria.[16] Excel was used for statistical analysis.

\section{Results}

Of the 192 websites evaluated (152 allopathic and 40 osteopathic schools), websites contained a mean of 23 items (59\%) with a standard deviation of 4.2 items. We found a statistically significant difference between allopathic and osteopathic programs $(p<0.05)$ for 6 of the 39 variables included in our study, which were USMLE Step 1 pass rate, facility description, research requirement information listed, scholarship opportunities listed, waitlist information provided, and early decision information provided. The variables contained least frequently among all medical schools were average financial aid amount (3.6\%), average United States Medical Licensing Examination (USMLE) Step 1 score (6.8\%), USMLE Step 1 pass rate (15.6\%), and US News and World Report ranking (15.6\%). The variables contained most frequently were yearly overview $(96.9 \%)$, required pre-medical courses $(96.4 \%)$, admissions office contact information (94.8\%), and information on how to apply for financial aid (93.2\%) [Table 1].

The categories with the most amount of information across both allopathic and osteopathic schools were the social and financial aid categories, with $81 \%$ and $69 \%$ of websites containing this information, respectively. The categories with the least number of variables was the curriculum and research categories at $50 \%$ and $54 \%$ respectively. Allopathic websites were more likely to contain variables relating to curriculum, research, demographics, admissions information, and faculty, while osteopathic websites were more likely to contain information in the financial aid and social categories [Figure 1].

Medical school websites from US News and World Report top 25 schools contained more of the 39 variables than schools from non-top 25 programs, with statistical significance demonstrated with variables such as research requirement, average financial aid, in-state vs out-of-state preference listed, and US News and World Report ranking listed [Table 2]. Medical school websites from top 25 schools had more variables listed on average in each of the seven general categories when compared to the other nontop 25 programs [Figure 2]. 
Table 2

A comparison of variables found on top 25 medical school websites compared to other non-top 25 school websites.

\begin{tabular}{|llll} 
Comparison Variables & $\begin{array}{l}\text { Number of Top 25 } \\
\text { Programs (\% of all Top 25 } \\
\text { Programs) }\end{array}$ & $\begin{array}{l}\text { Number of Non-Top 25 Programs } \\
\text { (\% of all Non-Top 25 Programs) }\end{array}$ & $\begin{array}{l}\text { P } \\
\text { value }\end{array}$ \\
\hline
\end{tabular}

\section{Curriculum}

\begin{tabular}{|c|c|c|c|}
\hline Yearly Overview Listed & $25(100.0 \%)$ & $161(96.4 \%)$ & 0.702 \\
\hline $\begin{array}{l}\text { Attendance Policy } \\
\text { Listed }\end{array}$ & $12(48.0 \%)$ & $40(24.0 \%)$ & 0.076 \\
\hline $\begin{array}{l}\text { Evaluation (Grading) } \\
\text { Policy Listed }\end{array}$ & $13(52.0 \%)$ & $52(31.1 \%)$ & 0.201 \\
\hline $\begin{array}{l}\text { Dual Degree Programs } \\
\text { Listed }\end{array}$ & $25(100.0 \%)$ & $123(73.7 \%)$ & 0.394 \\
\hline Match results listed & $17(68.0 \%)$ & $115(68.9 \%)$ & 0.612 \\
\hline $\begin{array}{l}\text { Average USMLE Step } 1 \\
\text { Score }\end{array}$ & $1(4.0 \%)$ & $12(7.2 \%)$ & 0.489 \\
\hline $\begin{array}{l}\text { USMLE Step } 1 \text { Pass } \\
\text { rate }\end{array}$ & $3(12.0 \%)$ & $27(16.2 \%)$ & 0.490 \\
\hline Average COMLEX score & - & $4(10.0 \%)$ & - \\
\hline $\begin{array}{l}\text { COMLEX pass rate } \\
\text { listed }\end{array}$ & - & $34(85.0 \%)$ & - \\
\hline Facility Description & $12(48.0 \%)$ & $93(55.7 \%)$ & 0.382 \\
\hline $\begin{array}{l}\text { Rotation Information } \\
\text { Provided }\end{array}$ & $22(88.0 \%)$ & $119(71.3 \%)$ & 0.691 \\
\hline
\end{tabular}

\section{Research}

Description of Research $21(84.0 \%)$

$138(82.6 \%)$

0.661

Opportunities

\section{Research Requirement $17(68.0 \%)$ \\ Information Listed \\ Demographics of Incoming Class}

$31(18.6 \%)$

0.000

\begin{tabular}{lccc}
$\begin{array}{l}\text { Demographics are } \\
\text { listed }\end{array}$ & $21(84.0 \%)$ & $96(57.5 \%)$ & 0.278 \\
\hline MCAT Stats Listed & $18(72.0 \%)$ & $122(73.1 \%)$ & 0.597 \\
\hline GPA Stats Listed & $19(76.0 \%)$ & $122(73.1 \%)$ & 0.747 \\
\hline $\begin{array}{l}\text { State-by-State Data } \\
\text { Listed }\end{array}$ & $7(28.0 \%)$ & $29(17.4 \%)$ & 0.392 \\
\hline
\end{tabular}




\section{Comparison Variables Number of Top 25 Programs (\% of all Top 25 Programs) \\ Number of Non-Top 25 Programs (\% of all Non-Top 25 Programs) \\ $P$ value}

\section{Financial Aid}

Average Financial Aid $\quad 4(16.0 \%)$

$3(1.8 \%)$

0.001

Listed

Info on How to Apply 23 (92.0\%)

$156(93.4 \%)$

0.548

For Aid Listed

Financial Aid Office

$23(92.0 \%)$

$151(90.4 \%)$

0.650

Contact Info Listed

Scholarship
Opportunities Listed

$16(64.0 \%)$

$120(71.9 \%)$

0.377

Example Budget Listed

$23(92.0 \%)$

$147(88.0 \%)$

0.739

Admissions Info

Required Pre-Med

Courses Listed

$23(92.0 \%)$

$162(97.0 \%)$

0.440

Letters of Rec

$25(100.0 \%)$

$153(91.6 \%)$

0.884

Requirements Listed

Admissions Office

Contact Info listed

$25(100.0 \%)$

$157(94.0 \%)$

0.790

Waitlist Information

Provided

$7(28.0 \%)$

$53(31.7 \%)$

0.543

Early Decision Program 13 (52.0\%)

$83(49.7 \%)$

0.805

Info Provided

Acceptance Rate Listed

$14(56.0 \%)$

$79(47.3 \%)$

0.864

In vs Out-of-State

$4(16.0 \%)$

$67(40.1 \%)$

0.035

Preference listed

Interview/Decision

Timing Listed

U.S. News Ranking

Listed

$23(92.0 \%)$

$109(65.3 \%)$

0.327

Social

Student Wellness

Resources Listed

Med School Social

Media link(s) Listed

$12(48.0 \%)$

$18(10.8 \%)$

0.000

$22(88.0 \%)$

$150(89.8 \%)$

0.541

$23(92.0 \%)$

$139(83.2 \%)$

0.933 


\begin{tabular}{|llll|}
\hline Comparison Variables & $\begin{array}{l}\text { Number of Top 25 } \\
\text { Programs (\% of all Top 25 } \\
\text { Programs) }\end{array}$ & $\begin{array}{l}\text { Number of Non-Top 25 Programs } \\
\text { (\% of all Non-Top 25 Programs) }\end{array}$ & $\begin{array}{l}\text { P } \\
\text { value }\end{array}$ \\
\hline $\begin{array}{l}\text { Description of Area } \\
\text { Activities/Highlights } \\
\text { Listed }\end{array}$ & $22(88.0 \%)$ & $112(67.1 \%)$ & 0.512 \\
\hline $\begin{array}{l}\text { Clubs/Interest Groups } \\
\text { Listed }\end{array}$ & $23(92.0 \%)$ & $132(79.0 \%)$ & 0.884 \\
\hline Faculty & $20(80.0 \%)$ & $149(89.2 \%)$ & 0.337 \\
\hline Faculty Listed & $18(72.0 \%)$ & $126(75.4 \%)$ & 0.510 \\
\hline Photos Listed & $8(32.0 \%)$ & $29(17.4 \%)$ & 0.213 \\
\hline $\begin{array}{l}\text { Student/Faculty Ratio } \\
\text { Listed }\end{array}$ & $18(72.0 \%)$ & $114(68.3 \%)$ & 0.796 \\
\hline $\begin{array}{l}\text { Faculty Research } \\
\text { Interests Listed }\end{array}$ & & & \\
\hline
\end{tabular}

Lastly, in-terms of website accessibility, $89 \%$ of medical school program listings on the MSAR database or the AOA website provided direct links, $10 \%$ provided absent or non-functional links, and $1 \%$ provided indirect links.

\section{Discussion}

As medical school applicants apply to, interview at, and ultimately decide which institution to attend, careful planning and research is essential. The internet is easily accessible and multiple studies have shown the importance of websites in recruitment for residency, $5,8,9$ which likely applies to students applying for medical school as well. This will likely be of growing importance in the wake of the COVID-19 pandemic, as in-person methods of evaluating prospective institutions are being replaced with virtual means. Medical schools spend a substantial time and effort recruiting competitive and diverse students throughout the year with advertisements, information sessions, carefully planned interview days, secondlook weekends, phone calls, financial aid offers, and more.[19] While these efforts will continue to be important, maintaining a medical school website with adequate information and quality is paramount, particularly for today's prospective student. For example, a survey of medical school students applying for residency found that $41 \%$ of applicants decided not to apply to at least one program solely based on the quality of its residency website, and $78 \%$ of applicants claimed information provided in the residency program website influenced their decision to apply to a particular program.[20]

A recent study examining prospective students' medical school preferences reported the most important factors for medical school choice were academic prestige, location, and the "intangibles," such as "gut feelings" and personal interactions.[21] According to our study, medical schools rarely included US News and World Report rankings on their websites, average USMLE Step 1 score, or USMLE Step 1 pass/fail 
rate. These factors, which are associated with the prestige of the school, should be incorporated onto medical school websites. With regards to location, medical schools provided descriptions of the location of the medical school nearly $70 \%$ of the time. This becomes increasingly important with online interviews as many applicants may not be able to see the area for themselves. Another area for improvement for medical school websites could be providing state-by-state demographic information, which was only listed $19 \%$ of the time. However, the "intangibles," such as "gut feelings" and personal interactions were student wellness resources listed, clubs and interest groups, and social media links which were listed $90 \%, 81 \%$ and $84 \%$ of the time. This shows medical schools are likely aware of the "intangibles" and attempt to address them with more personal and social content.

With the rise of social media for recreational and professional purposes, integrating social media effectively and efficiently could help medical schools recruit desired applicants and help applicants learn more about different schools. We found $84 \%$ of medical schools' websites contained links to a form of social media representing their program, but $16 \%$ of programs did not have a directly accessible social media page for their program. This suggests an area for improvement. Having a social media site available for applicants could prove useful to students and programs, as a study done involving nearly 1000 medical students applying for residency showed that $68 \%$ of students reported using social media to learn about programs and $10 \%$ reported that the information found in the social media pages influenced their decisions on where to apply.[22] Similarly, a survey of medical students applying for residency suggested social media as an efficient method for highlighting social activities to improve recruitment.[23]

Information on current enrolled medical students, such as class demographics and state-by-state data, may be the only exposure of such applicants to the unique personalities and backgrounds of students in the program before deciding to apply to a program. Class demographics and state-by-state data were only listed on $61 \%$ and $19 \%$ of medical school websites, respectively. Medical schools may benefit from improving these sections of their websites. We also found medical school websites do not have much information pertaining to individual students. However, many residency websites often include photos of the class, photos of each individual student, and small, personal descriptions of each resident. This is an area for medical school websites to give more personalization to their program. Of course, maintaining appropriate confidentiality of the students should be considered.

Additionally, we found curriculum and research were not adequately addressed on medical school websites. For example, attendance policy was only listed on $27 \%$ of websites, grading policies were listed on $34 \%$ of websites, and research requirement information was listed on $25 \%$ of websites. As medical education becomes more personalized to the needs of individual students, understanding the individual needs of students, details such as lecture attendance policy, grading policies, and research requirements are helpful details that could help applicants choose which programs to apply to based on their unique learning style.[24-26] These details are essential as applicants choose to which programs they will apply. Also, while many of these topics are discussed during interviews, these details can be forgotten or unclear, and a more robust website would be useful in addressing these important questions when 
medical students are deciding which school to attend. Including more information on curriculum and research could help medical students decide which programs to apply to and attend and help programs recruit students who are a better fit for the curriculum of the school. Recent articles have suggested that residency programs expand the amount of information for applicants during the COVID-19 interview cycle, and perhaps the same should apply to medical schools.[27]

While some aspects of medical school websites are lacking, we found medical school websites are very accessible through the MSAR database and the AOA website. Of the 192 medical schools examined in our study, $89 \%$ of medical school program listings in AOA or MSAR provided direct links, while only $10 \%$ were absent or non-functional, and $1 \%$ were indirect links. However, the number of multiple-step, absent, and non-functional links could still be improved.

The top 25 schools in the United States according to United States News and World Report 2021 had more study variables listed on their websites than non-top 25 schools, such as information on the research requirement and average financial aid. In addition, allopathic websites were more likely to contain variables relating to curriculum, research, demographics, admissions information, and faculty, while osteopathic websites were more likely to contain information in the financial aid and social categories. Future investigation should determine why these differences exist, and whether these differences affect prospective student recruitment.

Future research should aim to determine how the COVID-19 pandemic and lack of online information on medical school websites could be affecting the number of applications submitted per applicant.

Limitations of our study include the subjective nature of analyzing medical school websites. However, we feel our method of data collection was standardized sufficiently to control for ambiguity. Another limitation was the lack of established standardized criteria for evaluating websites. Every item that could be important to a medical school applicant was not analyzed. As a solution, we included a variety of items and developed search criteria based on studies evaluating residency website content and the recent experience of the authors of our study. Lastly, only including items listed directly on the medical school website rather than on external links could underestimate the presence of items on websites in our study. However, this was an important factor to determine the accessibility of information and user-friendly status of the websites. Our study does not address accuracy or quality of information contained on websites. Notwithstanding these limitations, we believe our analysis provides valuable insight for medical school directors, website developers, and medical school applicants. Future areas of study could include an in-depth analysis of social media use among medical schools, how website quality affects the number of medical school applications, and why differences in website content exist between different programs, such as allopathic, osteopathic, and US News and World Report top 25 schools.

\section{Conclusion}

The 2020-21 residency application cycle poses a new challenge for applicants and programs. A study examining residency interview costs discovered four in ten students decline interviews for financial 
reasons.[28] As most interviews are being conducted on a virtual platform, interview costs are less of an issue for applicants, which could drive up the number of programs students apply to and consider. Recent reports estimate a $14 \%$ increase in the number of medical school applications to AAMC compared to last year.[29] The sheer number of applications could overwhelm medical schools and increase competition for an already limited number of interview slots. As economic barriers of travel costs are brought down by the virtual interview mandate, students have the opportunity to apply to and attend more interviews. However, interview slots could potentially be taken up by a smaller pool of applicants. Now more than ever, a robust source of information available to applicants on medical school websites serves to benefit both applicant and program alike to prevent overwhelming medical schools with applications and interviewees.[30]

Medical school website quality is important to medical school applicants, and our study identifies several areas where programs could focus efforts for website renovation, including improving the integration of social media and improving information on the curriculum and policies of the school. The results from our study can be used to improve medical school websites to the benefit of applicants and medical schools.

\section{Declarations}

Ethics approval and consent to participate: IRB approval was not required for our study based on Mayo Clinic IRB guidelines

Consent for Publication: Not applicable

Availability of data and materials: Data sharing is not applicable to this article as no datasets were generated or analyzed during the current study

Competing interests: None

Funding: none

Authors contributions: All authors contributed to the creation and implementation of the project design and implementation. JP and LM were responsible for statistical analysis, tables, and figures. All authors were responsible for critical revision and contribution to the final draft of this manuscript. All authors read and approved this final manuscript.

Acknowledgements: Not applicable

Conflicts of Interest: None

\section{References}


1. 2019 FACTS: Applicants and Matriculants Data. AAMC. https://www.aamc.org/datareports/students-residents/interactive-data/2019-facts-applicants-and-matriculants-data. Accessed 9 Aug 2020.

2. Deciding Where to Apply. https://students-residents.aamc.org/applying-medical-school/applyingmedical-school-process/deciding-where-apply/. Accessed 9 Aug 2020.

3. New! Reports from the Coalition for Physician Accountability - The Match, National Resident Matching Program. http://www.nrmp.org/coalition-physician-accountability-documents/. Accessed 30 Jun 2020.

4. Silvestre J, Tomlinson-Hansen S, Fosnot J, Taylor JA. Plastic surgery residency websites: a critical analysis of accessibility and content. Ann Plast Surg. 2014;72:265-9.

5. Svider PF, Gupta A, Johnson AP, Zuliani G, Shkoukani MA, Eloy JA, et al. Evaluation of Otolaryngology Residency Program Websites. JAMA Otolaryngol Neck Surg. 2014;140:956-60.

6. An Assessment of the Comprehensiveness of Radiation Oncology Residency Websites. https://appliedradiationoncology.com/articles/an-assessment-of-the-comprehensiveness-ofradiation-oncology-residency-websites. Accessed 3 Jul 2020.

7. An Evaluation of the Content of Canadian and American Nuclear Medicine Fellowship Websites Saira Hamid, Brian Gibney, Bonnie Niu, Rachel Phord-Toy, Nicolas Murray, Arvind Vijayasarathi, Savvas Nicolaou, Faisal Khosa,. https://journals.sagepub.com/doi/abs/10.1177/0846537120913031. Accessed 31 May 2020.

8. Khan MS, Hayat J, Marsia S, Yamani N, Doukky R, Butler J, et al. How well do we represent ourselves: an analysis of cardiology fellowships website content. Future Cardiol. 2020.

9. Oladeji LO, Yu JC, Oladeji AK, Ponce BA. How Useful are Orthopedic Surgery Residency Web Pages? J Surg Educ. 2015;72:1185-9.

10. Patel BG, Gallo K, Cherullo EE, Chow AK. Content Analysis of ACGME Accredited Urology Residency Program Webpages. Urology. 2020;138:11-5.

11. How COVID-19 is affecting medical school admissions. American Medical Association. https://www.ama-assn.org/residents-students/preparing-medical-school/how-covid-19-affectingmedical-school-admissions. Accessed 13 Sep 2020.

12. | Medical School Admission Requirements. https://apps.aamc.org/msar-ui/\#/landing. Accessed 9 Aug 2020.

13. Osteopathic Medical Schools. American Osteopathic Association. https://osteopathic.org/about/affiliated-organizations/osteopathic-medical-schools/. Accessed 9 Aug 2020.

14. Deloney LA, Perrot LJ, Lensing SY, Jambhekar K. Radiology Resident Recruitment: A Study of the Impact of Web-based Information and Interview Day Activities. Acad Radiol. 2014;21:931-7.

15. Zigrossi D, Ralls G, Martel M, Rothrock SG, Langdorf MI, Cheaito MA, et al. Ranking Programs: Medical Student Strategies. J Emerg Med. 2019;57:e141-5. 
16. Best Medical Schools (Research) Ranked in 2021 - US News Rankings. https://www.usnews.com/best-graduate-schools/top-medical-schools/research-rankings. Accessed 9 Aug 2020.

17. Embi PJ, Desai S, Cooney TG. Use and Utility of Web-Based Residency Program Information: A Survey of Residency Applicants. J Med Internet Res. 2003;5. doi:10.2196/jmir.5.3.e22.

18. Cleary MX, Yi PH, Ahlawat S. Evaluation of Musculoskeletal Radiology Fellowship Websites. Curr Probl Diagn Radiol. 2020. doi:10.1067/j.cpradiol.2020.02.010.

19. Medical School Interviews. https://students-residents.aamc.org/applying-medical-school/applyingmedical-school-process/medical-school-interviews/. Accessed 12 Sep 2020.

20. Gaeta TJ, Birkhahn RH, Lamont D, Banga N, Bove JJ. Aspects of residency programs' web sites important to student applicants. Acad Emerg Med Off J Soc Acad Emerg Med. 2005;12:89-92.

21. Brown C. A qualitative study of medical school choice in the UK. Med Teach. 2007;29:27-32.

22. The Role of Social Networking Web Sites in Influencing Residency Decisions | The Journal of the American Osteopathic Association. https://jaoa.org/article.aspx?articleid=2094493. Accessed 1 Jun 2020.

23. Mahler SA, Wagner M-J, Church A, Sokolosky M, Cline DM. Importance of residency program web sites to emergency medicine applicants. J Emerg Med. 2009;36:83-8.

24. Haiech J, Kilhoffer M-C. Personalized medicine and education: the challenge. Croat Med J. 2012;53:298-300.

25. Yovanoff M, Pepley D, Mirkin K, Moore J, Han D, Miller S. Personalized Learning in Medical Education: Designing a User Interface for a Dynamic Haptic Robotic Trainer for Central Venous Catheterization. Proc Hum Factors Ergon Soc Annu Meet Hum Factors Ergon Soc Annu Meet. 2017;61:615-9.

26. Toward More Personalized Learning. https://www.hopkinsmedicine.org/news/articles/toward-morepersonalized-learning-1. Accessed 12 Sep 2020.

27. Hammoud MM, Standiford T, Carmody JB. Potential Implications of COVID-19 for the 2020-2021 Residency Application Cycle. JAMA. 2020;324:29-30.

28. Fogel HA, Liskutin TE, Wu K, Nystrom L, Martin B, Schiff A. The Economic Burden of Residency Interviews on Applicants. lowa Orthop J. 2018;38:9-15.

29. Med School Applications Soaring. 2020. https://www.medpagetoday.com/publichealthpolicy/medicaleducation/88140. Accessed 12 Sep 2020.

30. Davis MG, Haas MRC, Gottlieb M, House JB, Huang RD, Hopson LR. Zooming In Versus Flying Out: Virtual Residency Interviews in the Era of COVID-19. AEM Educ Train. n/a n/a. doi:10.1002/aet2.10486.

\section{Figures}




\section{Content on Osteopathic and Allopathic Medical School Websites}

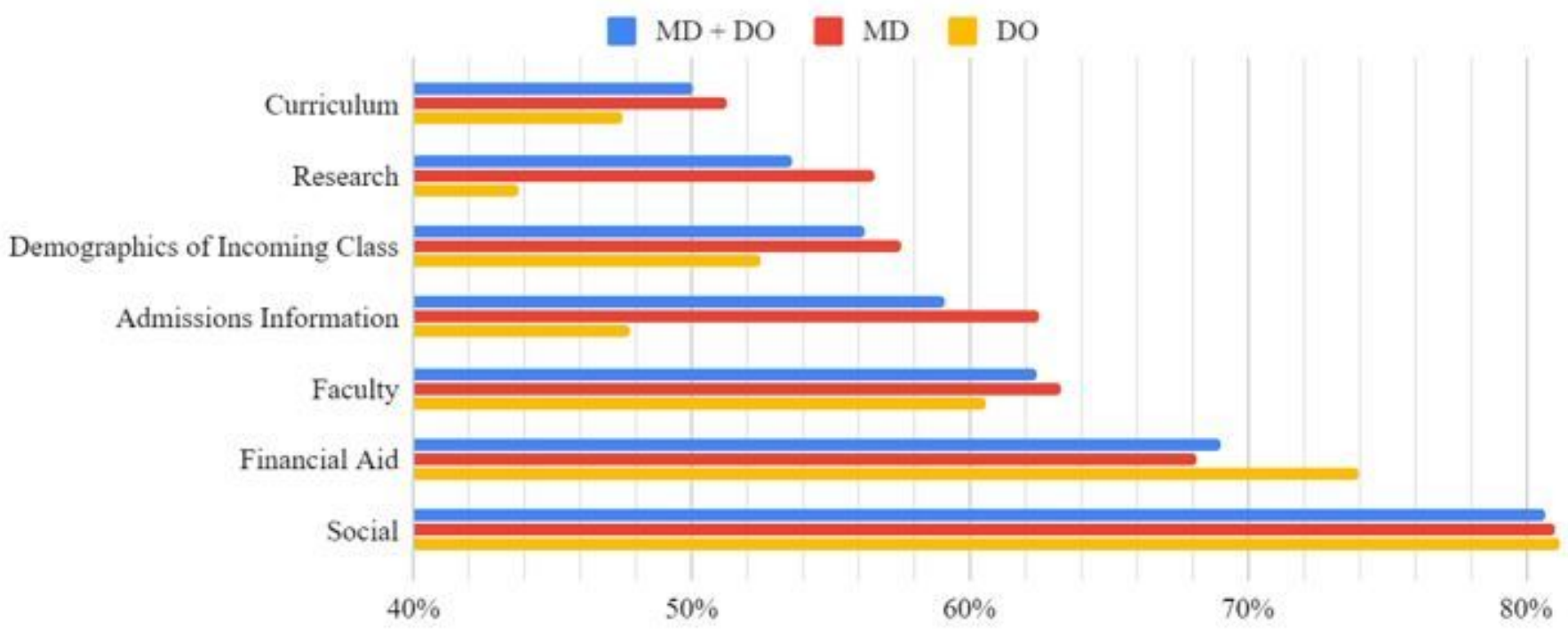

Figure 1

Content analysis comparing osteopathic and allopathic medical school websites.

\section{Content on Top 25 Ranked vs All Other Medical School Websites}

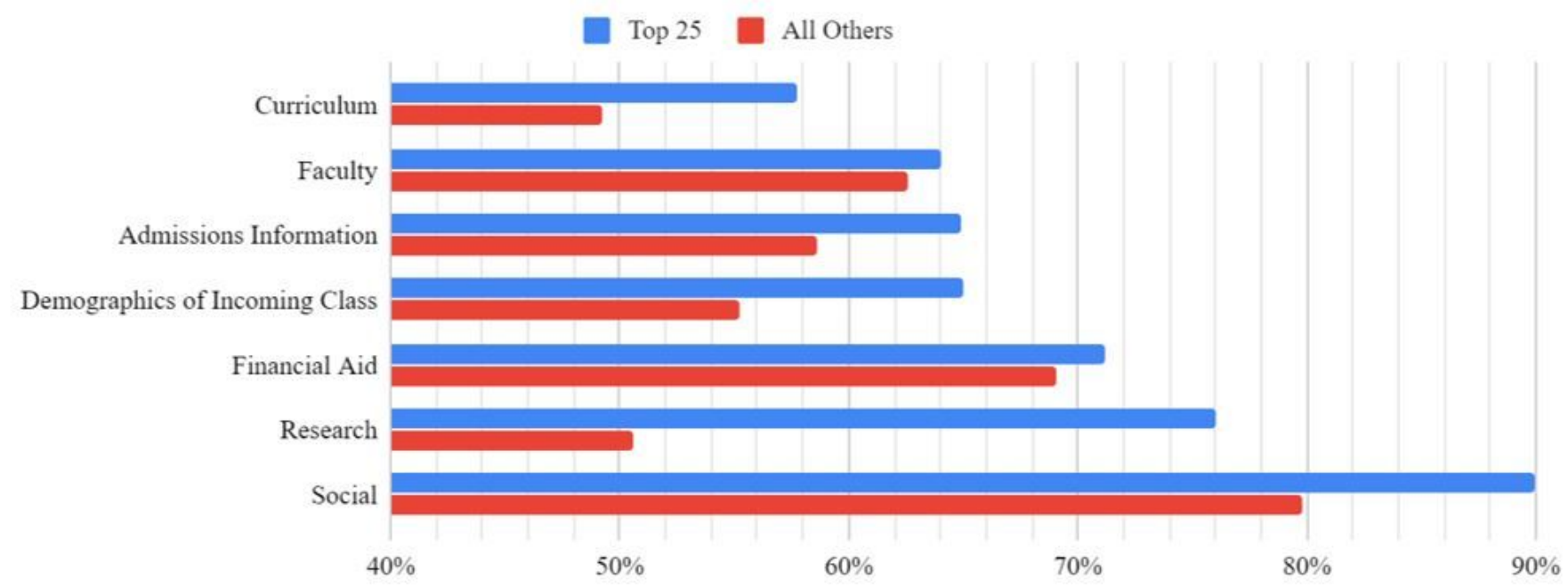

Figure 2

A comparison of variables found on top 25 medical school websites compared to other non-top 25 school websites. 